\title{
GROSS AND HISTOLOGICAL STUDY OF CORONARY SINUS AND ITS CLINICAL RELEVANCE
}

\author{
Harsh Kumar Chawre', Vishal Bhadkaria², S. D. Joshi³, S. S. Joshi ${ }^{4}$
}

${ }^{1}$ Tutor, Department of Anatomy, Sri Aurobindo Medical College \& PG Institute.

${ }^{2}$ Post Graduate Student, Department of Anatomy, Sri Aurobindo Medical College \& PG Institute.

${ }^{3}$ Dean \& Professor, Department of Anatomy, Sri Aurobindo Medical College \& PG Institute.

${ }^{4}$ Professor \& HOD, Department of Anatomy, Sri Aurobindo Medical College \& PG Institute.

\section{ABSTRACT}

The coronary sinus is important in many electrophysiological procedures including arrhythmia ablation, biventricular pacing and for deployment of an array of cardiac devices. The advent of advanced invasive and interventional cardiac treatment and management tools for common disorders like heart failure has made understanding of CS anatomy necessary.

\section{MATERIAL AND METHODS}

The study has been conducted in fifty normal hearts available. Length of CS was measured. CS ostium and the Thebesian valve were exposed and measurements taken. Histological study of CS was done.

\section{RESULT AND CONCLUSION}

The presence of myocardial fibres in the wall of CS and their arrangement in the form of circular, longitudinal and tangentially arranged fibres may have regulating function on the flow of blood in the CS. The connection of the muscle fasciculi with the left and the right atrium may have selective role in the conduction and act as an accessory pathway.

In the present study the average length of the CS was $30 \mathrm{~mm}$; in the majority (96.0\%) the CS ostium was oval. In most of the cases $(84.0 \%)$ CS ostium was guarded by thebesian valve, which was semilunar in shape $(74 \%)$. The valve covered variable area of the ostium.

\section{KEYWORDS}

Coronary Sinus, Thebesian Valve, Coronary Ostium, Arrythmias, Interventional Cardiology.

HOW TO CITE THIS ARTICLE: Harsh Kumar Chawre, Vishal Bhadkaria, S. D. Joshi, S. S. Joshi. “Gross and Histological Study of Coronary Sinus and its Clinical Relevance." Journal of Evolution of Medical and Dental Sciences 2015; Vol. 4, Issue 101, December 17; Page: 16655-16661, DOI: 10.14260/jemds/2015/2486

\section{INTRODUCTION}

The Coronary Sinus (CS) has become a clinically important structure, especially through its role in providing access for different cardiac procedures. The coronary venous system is important in many electrophysiological procedures, including arrhythmia ablation, biventricular pacing, and for deployment of an array of cardiac devices. The advent of advanced invasive and interventional cardiac treatment and management tools for common disorders like heart failure has made understanding of CS anatomy necessary. ${ }^{1}$

Coronary Sinus (CS) has been known since antiquity to anatomists (Eristratos, 280 BC; Galeno, 129 AD). It displays anatomic characteristics of a true cardiac chamber. The sinus itself lies within the left atrioventricular groove. It is indeed not a vein, but a true small cardiac chamber. An intracameral conduction system with a coronary sinus node. ${ }^{2}$ and Purkinjetype fibers are also described and may be targets for the future study and ablation therapy of atrial arrhythmias. ${ }^{3}$ Opening of the CS lies between the orifice of the inferior venacava, the oval fossa and the vestibule of the atrioventricular opening and is often guarded by a thin, semicircular valve which covers the lower part of the orifice (Thebesian valve).,4,5

Financial or Other, Competing Interest: None.

Submission 28-11-2015, Peer Review 29-11-2015,

Acceptance 12-12-2015, Published 16-12-2015.

Corresponding Author:

Dr. S. D. Joshi,

204, Sapna Apartment,

39, Kailash Park Colony,

Indore-452001.

E-mail: sdjoshi_2003@hotmail.com

DOI:10.14260/jemds/2015/2486
The CS ostium is $5-15 \mathrm{~mm}$ anterior to the Eustachian ridge and valve and posterior to the tricuspid annulus.1,7 The Thebesian valve is highly variable and occasionally may present an obstruction during cannulation of the CS. ${ }^{8}$ The coronary sinus carries 60 per cent of the total coronary flow. ${ }^{9}$ The Thebesian valve always contains muscular fibres and its variations (Especially when the ostial valve of the middle cardiac vein is derived from it) may cause difficulties when pacing the coronary sinus. ${ }^{10}$

Coakley et al. (1946) had noticed that the structure of the CS showed myocardial fibers. ${ }^{11}$, specialized conduction cells, which participate in interatrial conduction and may be responsible for genesis of some arrhythmias.

Both CT and MRI provide excellent non-invasive depiction of the anomalies of CS. Several procedures make use of the CS, such as left ventricular pacing. ${ }^{12}$ mapping and ablation of arrhythmias. ${ }^{13}$ retrograde cardioplegia, targeted drug delivery, and stem cell therapy. ${ }^{14}$

\section{MATERIAL AND METHOD}

Fifty normal hearts, which were grossly normal and free from any pathology, available in the Department of Anatomy and also procured from the post mortem specimens from Forensic Medicine Department, were utilized for the present study. Clearance was obtained from Institutional Ethical Committee. Oblique vein of the left atrium was identified and length of CS was measured with the help of digital vernier caliper.

The right atrium was opened to examine the CS ostium and the Thebesian valve and various measurements were taken. The muscle fibres in the wall of CS were dissected visualizing them with the help of magnifying lens or loupe and its arrangement and relation to atrial musculature and left auricle was ascertained. 
The lumen of the CS was examined and the presence of valves and any other features like the ridges and folds seen were recorded and photographed.

For histological study small segments of the CS from its proximal, middle, distal parts, including the Thebesian valves were processed by routine histological techniques and 5-7 microns thick sections were cut and stained by $-\mathrm{H}$ and $\mathrm{E}$, Masson's Trichome and Orcein. ${ }^{14,15}$

\section{Review of Literature}

The coronary sinus commences at the point where the oblique vein of the left atrium joins the great cardiac vein. The sinus receives the middle and small cardiac veins close to its junction with the right atrium.4,5,6 The beginning of the CS is marked by either an outer constriction, the opening of the oblique vein of the left atrium or by the Vieussens valve internally. 16

The length of the CS varies from 3 to $5.5 \mathrm{~cm}$ and is dependent on the site of the drainage of the posterolateral vein. The diameter of the CS is also variable and is dependent on the loading conditions, presence and extent of atrial myocardium with the coronary vein. At the level of the A-V sulcus, the anterior surface of the CS is separated from the atrial and ventricular myocardium by connective and adipose tissue, precluding it from an intramural location in the atrioventricular sulcus. ${ }^{3}$ Bates RJ et al. (1977) stated that Pratt (1898) postulated that the myocardium was maintained not only by arterial flow but also by thebesian vessels and backflow through the coronary veins. ${ }^{17}$

\section{CS Ostium}

According to Maasarany et al. (2005) the ostium marked the base of Koch's triangle and had a mean height of $7 \mathrm{~mm}$ (5-9mm) and mean width of $12 \mathrm{~mm}(7-16 \mathrm{~mm})$. They also found that in $80 \%$ of specimens the coronary sinus was cylindrical in shape with the widest diameter towards its opening into the right atrium and in $20 \%$ it showed marked narrowing at the site of the Vieussens valve giving a funnel shape appearance. The great cardiac vein and the coronary sinus were commonly embedded in the subepicardial fat of the posterior atrioventricular groove. The coronary sinus as it passed to the right deviated slightly superiorly to become more related to the back of the left atrium before it coursed inferiorly to open into the right atrium. ${ }^{16}$

Sanket S. Shah et al. (2012) showed that the CS is variable in its size, morphology and anatomy. Congenital CS morphologic variants include the presence of a diverticulum, variations in shape including a wind sock-shape, filiform, varicoid or bifid CS and variations in its course such as a highriding CS.13

GS Mak et al. (2009) also observed considerable variations in the diameter of the CS ostium. Heart specimens with absent Thebesian valves tended to have larger CS ostia. ${ }^{18}$ Silver MA et al. (1988) had also observed that the maximum diameter of the CS ostium tended to vary inversely with the extent of the Thebesian valve. ${ }^{19}$

In their study Matsuyama et al. (2010) found the mean surface area and diameter of the CS opening to be $43.7 \pm 17.3 \mathrm{~mm}^{2}$ and $10.5 \pm 2.8 \mathrm{~mm}$, respectively. ${ }^{20}$

\section{Thebesian Valve}

In their study, Maasarany et al. (2005) showed that coronary sinus ostium was guarded by the Thebesian valve, which was seen in $87.5 \%$ of the cases as a thin semilunar fold $1.0 \mathrm{~mm}-$ $4.1 \mathrm{~mm}$ long, at the anteroinferior rim of the ostium. In $10 \%$ specimens the valve was in the form of a narrow circular rim surrounding the whole ostium and in only one case the valve cusp showed small fenestrations. The valve was absent in one case $(2.5 \%)$. When present the valve did not cover more than one third of the coronary sinus ostium. ${ }^{16}$

Mak et al. (2009) have noted a wide variety of Thebesian valve morphologies including remnant valves and valves that completely occluded the ostium. The Thebesian valve was absent in $27 \%$. When present (73\%), the Thebesian valve also differed greatly in its composition, being fibrous, fibromuscular and membranous as well as fenestrated. In $27 \%$ the valve was large and covered at least $75 \%$ of the CS ostium, whereas the valve covered $10 \%$ of the ostium in $18 \%$. Most Thebesian valves were semicircular in shape $(65 \%)$. In a minority of specimens, the valve was strand-like $(4 \%)$ or band-like structure (13\%). ${ }^{18}$

\section{Musculature Surrounding the Coronary Sinus}

Adrian Barcelo et al. (2004) observed that CS shows three discrete layers of endocardium, myocardium and epicardium. ${ }^{3}$ Antz M et al. (1998) have described in details the musculature of the CS and have shown that continuous CS musculature was visible along the length of the CS. The CS musculature is continuous with left atrial myocardium in the proximal portion of the coronary sinus and with right atrial myocardium at the coronary sinus ostium. ${ }^{21}$

Chauvin et al. (2000) stated that in all specimens, the venous wall of the coronary sinus was surrounded by a cuff of striated muscle extending from the ostium and connected to the left atrium: they ranged from 1 to 2 fascicles to a widely intermingled continuum (Thickness, $2.79 \pm 2 \mathrm{~mm}$; width, $2.91 \pm 3.5 \mathrm{~mm})$. The valve of Vieussens was found in 6 hearts at a mean distance of $3.4 \pm 3.2 \mathrm{~mm}$ from the distal extremity of the coronary sinus muscle cuff. 22

Adrian Barcelo et al. (2004) have described that Bachmann's bundle is continuous anatomically and electrically with the myocardial muscular bundleatriocoronary sinus bundle that links the base of the left atrial appendage to the myocardial musculature of the CS. They also described the presence of Purkinje-like cells coupled with the finding of node-like P cells and postulates the presence of a CS node having perhaps all of the known properties of automaticity seen in $\mathrm{A}-\mathrm{V}$ nodal or sinus nodal tissue. ${ }^{3}$ Ortale JR et al. (2001) found morphologically variable left atrial coronary sinus myocardial connection. This emphasizes the need for surgical dissection or catheter ablation in or around the coronary sinus to eliminate these connections. ${ }^{7}$

Therefore, the Bachmann's bundle from the left atrium through the atriocoronary sinus bundle and the striated musculature of the CS forms a close conductive circuit: right atrium $\rightarrow$ left atrium $\rightarrow$ CS $\rightarrow$ right atrium. This circuit may represent a pathway of abnormal conduction responsible for many atrial re-entry arrhythmias. ${ }^{3}$ Sun Y et al. (2002) found myocardial sleeves or cords that could serve as a connection between the ventricle and the CS myocardial coat forming a Coronary Sinus Accessory Pathway (CSAP). ${ }^{23}$

Not only AV nodal anatomy, but also the spatial distributions of the CS musculature, may have a role in the pathology of Atrioventricular Nodal Re-entrant Tachycardia (AVNRT). The transitional cells around the AV node and nodal extensions are associated with the formations of re-entrant circuits.

\section{RESULTS}

Coronary sinus was found located in the posterior part of the atrioventricular sulcus. It was sub-epicardial in position and surrounded by good quantity of adipose tissue (Fig. 1). Some branches of the circumflex artery were found running parallel to CS within the atrioventricular sulcus; some of them were placed deep to CS. 
The length of sinus was measured with the help of digital vernier caliper. The various parameters studied were: the presence or absence of thebesian valve and its configuration; the shape of CS ostium (Fig. 2), the area of the ostium covered by Thebesian valve (Fig. 3). The dimensions of CS ostium, the presence and prominence of eustachian ridge (Fig. 3) were also ascertained. The findings were recorded and photographs were taken as and when required.

The epicardium covering the CS was split open, very gently the adipose tissue surrounding the sinus was removed taking all the precautions to preserve the muscle fasciculi that were either running parallel to or encircling the sinus (Fig. 1). Whole length of sinus was dissected out from the AV groove for histological study and then it was divided into three parts - proximal, intermediate and distal parts and was processed separately and their wax blocks were prepared for obtaining longitudinal and transverse sections. Five to seven microns thick $(5-7 \mu)$ sections were taken and they were submitted for various staining procedures.

Following are the observations recorded from the gross and the microscopic examinations of the Coronary sinus:

Total number of specimen $=\mathbf{5 0}$.

(A) Length of Coronary Sinus in (mm).

Average Length $=29.82 \mathrm{~mm}$. (Range $=19.03-54.32 \mathrm{~mm}$.)

\section{(B) Shape of Coronary Sinus Ostium (Fig. 2).}

Circular $=2$ cases $(4.0 \%)$.

Oval $=48$ cases $(96.0 \%)$.

\section{(C) Diameter of CS Ostium (mm).}

Average Transverse diameter $=11.19 \mathrm{~mm}$. $($ Range $=4.02-$ $16.91 \mathrm{~mm}$.)

Average Vertical diameter $=7.92 \mathrm{~mm}$. $($ Range $=3.61-$ $15.12 \mathrm{~mm}$.)

(D) Thebesian Valve (Fig. 3).

Present $=42$ cases $(84.0 \%)$.

Absent $=8$ cases $(16.0 \%)$.

(E) Shape of Thebesian valve (Fig. 4).

Semilunar $(S)=37$ cases $(74.0 \%)$.

Fenestrated $(\mathrm{F})=3$ cases $(6.0 \%)$.

Fenestrated + Band shaped $(F+B)=2$ cases $(4.0 \%)$.

(F) Approximate area covered by the valve (Fig. 3).

$1 / 4$ or $25 \%=16$ cases $(32.0 \%)$.

$1 / 2$ or $50 \%=14$ cases $(28.0 \%)$.

$3 / 4$ or $75 \%=12$ cases $(24.0 \%)$.

(G) Width of Eustachian Ridge (Fig. 3).

Average thickness $=6.605 \mathrm{~mm}$. (Range $=3.05-10.46 \mathrm{~mm}$.)

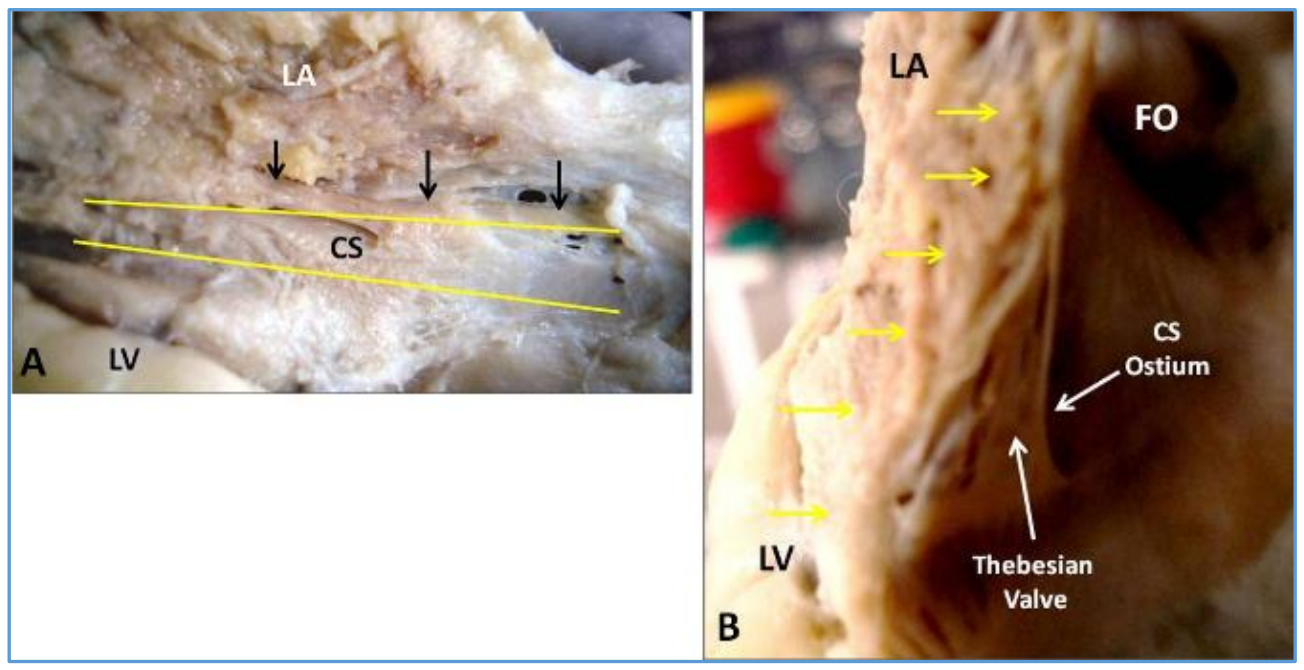

Fig. 1 (A): Thick muscle fasciculi extending from left to right atrium along the upper border of coronary sinus (Black arrows). CS = Coronary Sinus, LA = Left Atrium, LV = Left Ventricle. Fig. (B): Arching muscle fibres from Left Atrium (LA) (Yellow Arrows) to Left Ventricle (LV)
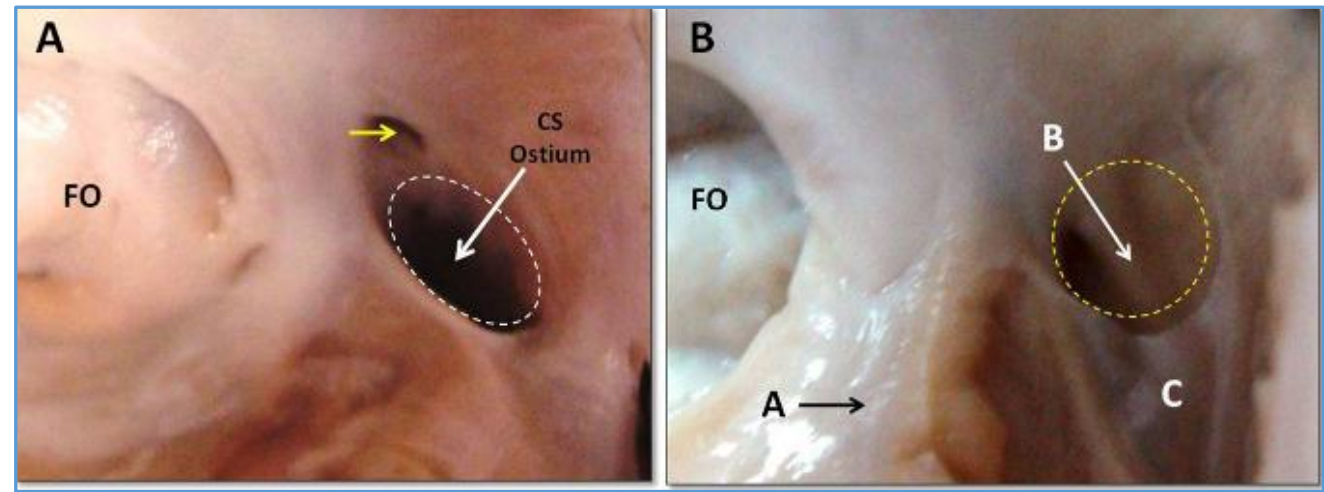

Fig. 2 (A): Photograph showing Oval opening of CS (White), FO = Fossa Ovalis. Opening of Thebesian vein (yellow arrow). Fig. (B): Photograph showing: Circular opening of CS (Yellow ring), $A=$ Eustachian Ridge, $B=$ CS Ostium, C $=$ Thebesian valve. FO = Fossa Ovalis 


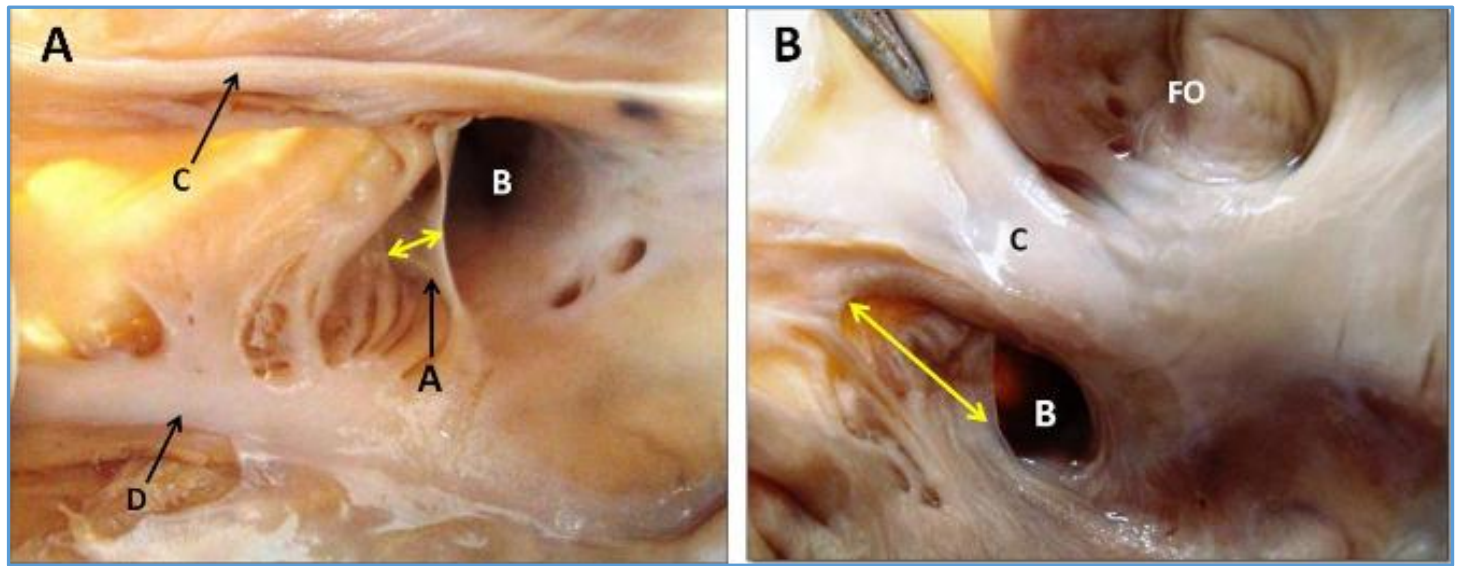

Fig. 3 (A): Photograph showing Thebesian valve $(A)$ is covering 1/4 of the CS Ostium (B), $C=$ Eustachian Ridge (Thin), $D=$ Tricuspid Annulus. Fig. (B): Photograph showing Thebesian valve (yellow arrow) covering 3/4 of the CS Ostium (B), C = Eustachian Ridge (Thick and Broad), FO = Fossa Ovalis
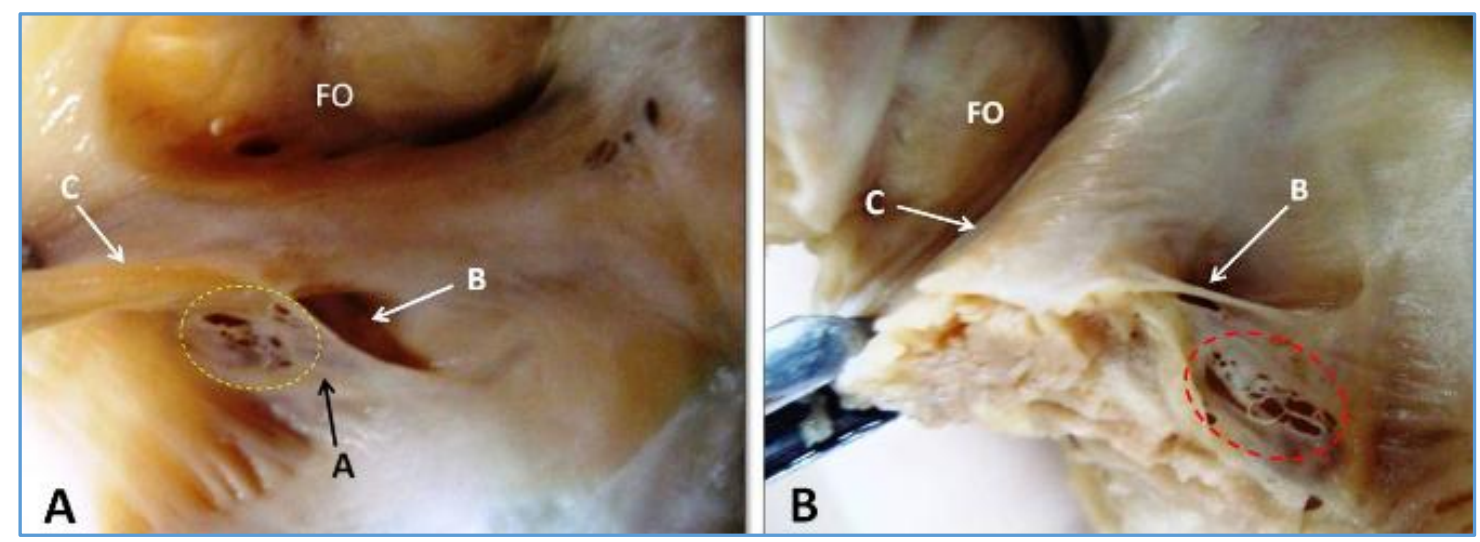

Fig. 4 (A): Photograph showing fenestrated Thebesian valve (Yellow ring), FO = Fossa Ovalis, $A=$ Thebesian valve, $B=C S$ Ostium, $C=$ Eustachian ridge. Fig. (B): Photograph showing Fenestrated (Red ring) Thebesian valve and Band like upper margin (B), FO = Fossa Ovalis, $C=$ Eustachian Ridge

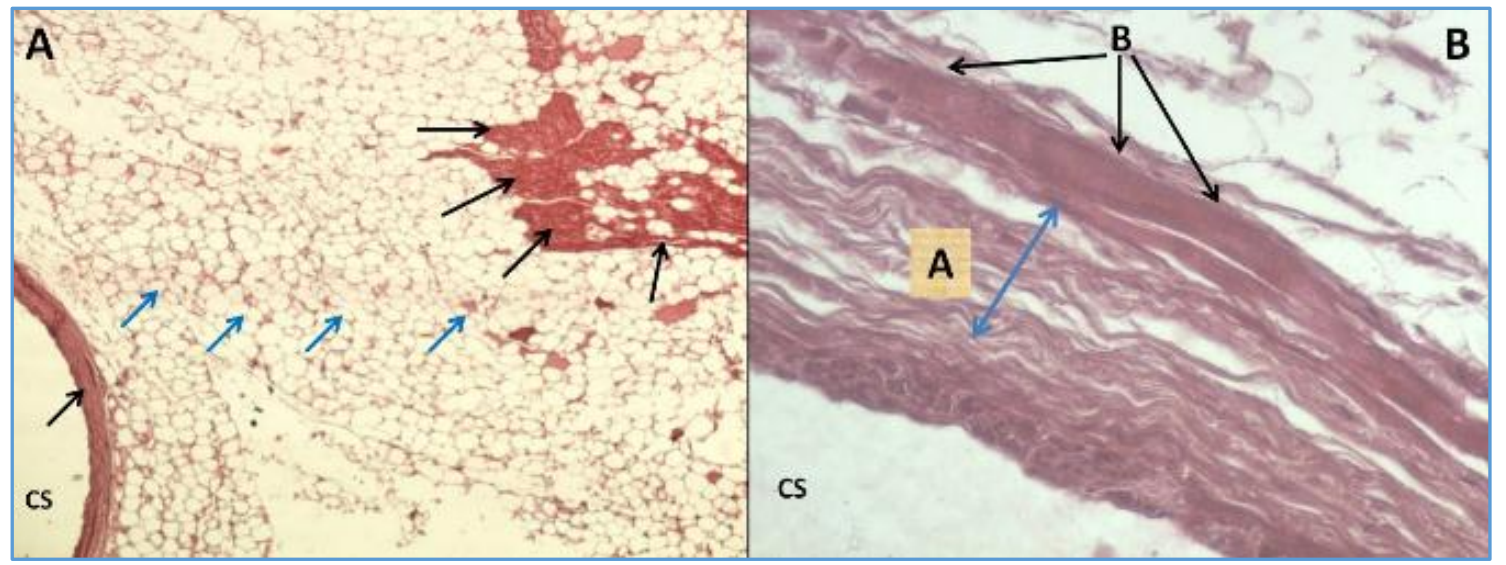

Fig. 5 (A): Photomicrograph showing TS of proximal part of CS. Fibrous wall of CS (A) being surrounded by thick layer of adipose tissue (Blue arrows), which separates it from the loose layer of Atrial musculature (Black arrows). (TS, $4 X, H \& E)$. Fig. (B): Photomicrograph showing the TS of proximal part of CS. Lumen of the CS is surrounded by layer of fibrous tissue (A), which in turn is surrounded by circularly arranged cardiac myocytes (B) showing transverse striations (Black arrow). (TS, 40X, H\&E) 


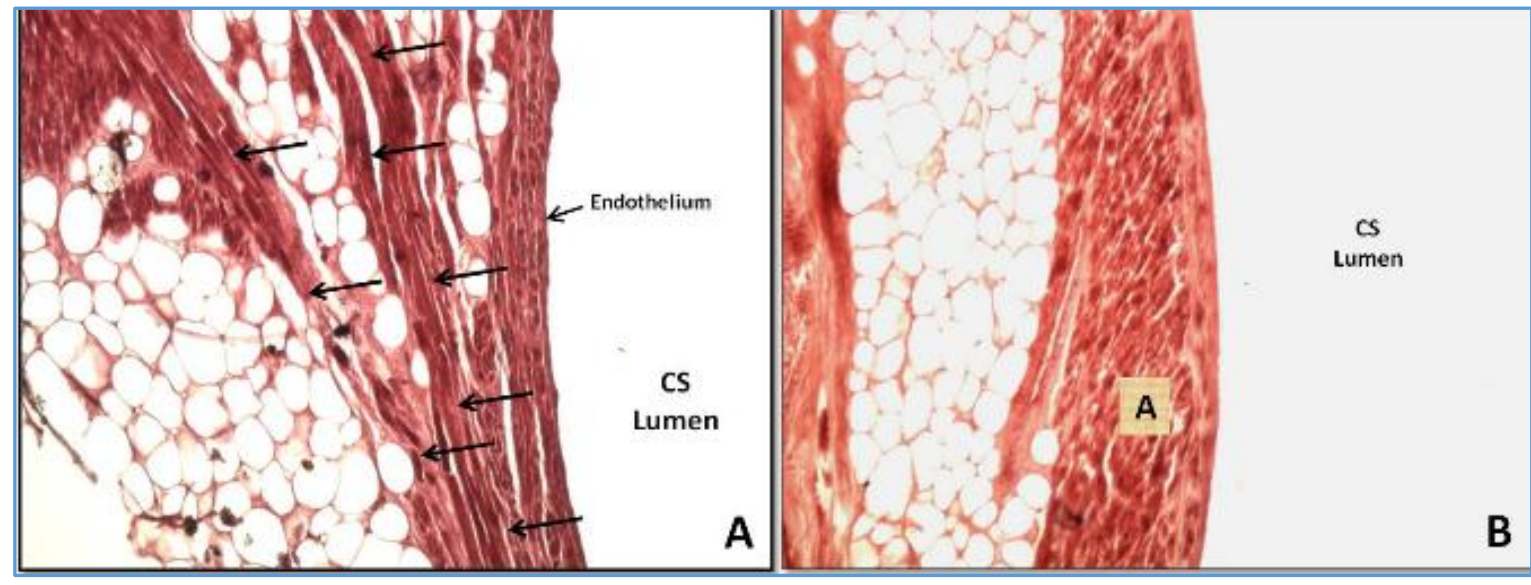

Fig. 6 (A): Photomicrograph shows TS from the intermediate part of CS showing the myocardial sleeve of CS being derived from atrial musculature (Black arrows). Adipose tissue is seen separating the layers of muscle fibres. (TS, 10X, H\&E). Fig. (B): Photomicrograph shows LS of intermediate part of CS. Wall of CS is being formed by thick layer of cardiac myocytes (A), which are running obliquely. (LS, $10 X, H \& E)$

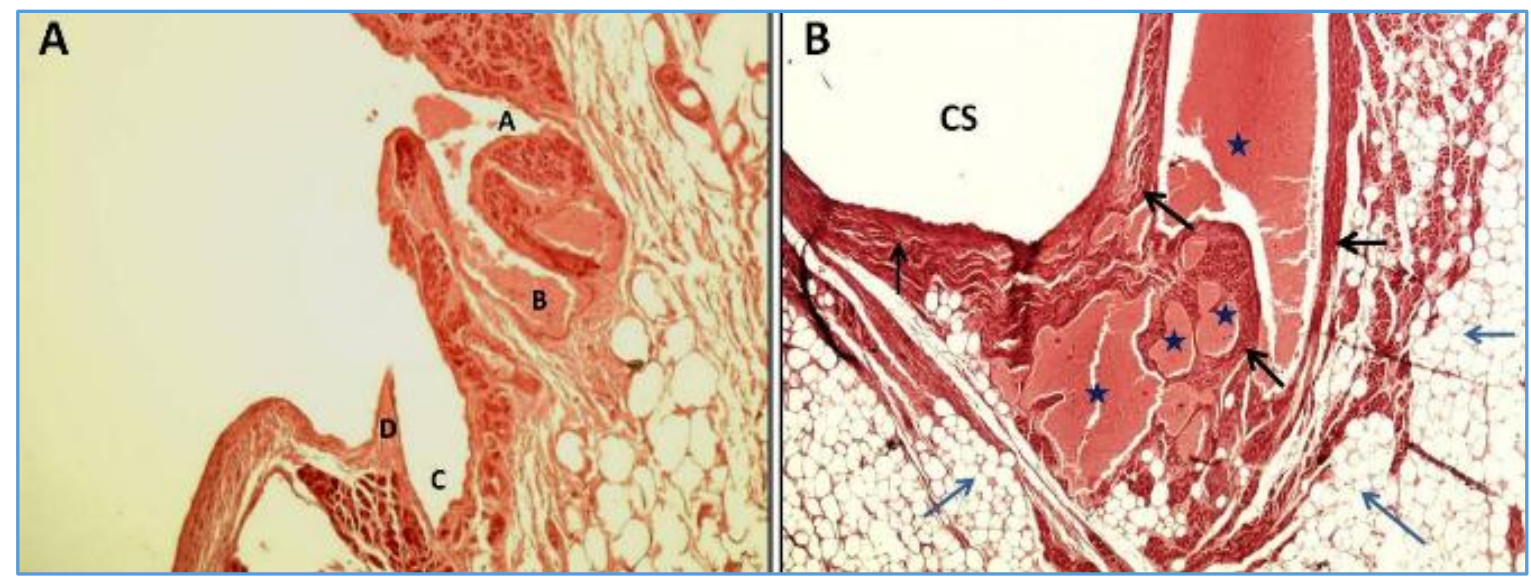

Fig. 7(A): Photomicrograph shows $L S$ of distal part of CS. Minute veins $(A, B, C)$ are seen opening into the CS. The vein $C$ at its entry point shows a valve (D) projecting in the lumen. (LS, 10X, H\&E). Fig. (B): This photomicrograph shows TS of distal part of CS. Surrounding the CS, there are multiple layers of myocardial cells (Black arrows). Between the muscle fasciculi and outside there is a layer of adipose tissue (Blue arrows) also seen are the cut sections of diverticulae (shown by *) of CS within the thick myocardial sheath. (TS, $4 X, H \& E)$

\section{HISTOLOGY}

At its commencement CS has a thin wall, being surrounded by adipose tissue all around and was made up of fibrous tissue (Fig. 5A); in one-third of the circumference the fibrous tissue was covered by one or two layers of myocardial fibres (Fig. $5 A$ ). No fibres from the sinus wall could be traced upto the atrial myocardium. When the CS is seen in longitudinal sections then at its proximal end, termination of Great Cardiac Vein (GCV) was seen, which was marked by the presence of valve of Vieussens. Oblique vein of left atrium was found to open at the confluence of CS and GCV. The CS is lined by flattened endothelium, which on the outside is covered by the thin coat of fibrous tissue. This in turn is again covered by a thick coat of longitudinally arranged cardiac muscle fibres (Fig. 5B).

In its intermediate part, the wall of the sinus was quite thick and was covered by a layer of areolar connective tissue of varying thickness. A thick layer of circularly arranged cardiac myocytes surrounded the CS. Left atrial myocardial fibres, in the form of muscle fasciculi of varying thickness were seen to approach the wall of CS (Fig. 6A). Some of these fasciculi were arranged tangential to the wall (Fig. 6A), while others formed a layer of circularly arranged fibres (Fig. 6B); yet there were others which formed a longitudinal coat (Fig. $6 \mathrm{~A}, 6 \mathrm{~B}$ ). Between many of these fasciculi small amount of adipose tissue was seen at places. A layer of fatty areolar tissue was seen to surround this wall of CS (Fig. 6A, 6B). In these histological sections, it was very difficult to trace either the origin or the termination of these fibres. Some of the cardiomyocytes in the wall were very long and few of these cells were very thick. The transverse striations were very distinctly visible (Fig. 6A, 6B). It was not possible to ascertain the presence of nodal fibres amongst these myocytes.

At the site of termination of thin walled veins, the opening was seen surrounded by circular sleeve of muscle fibres (Fig. 7A). At the confluence of some veins, a thin fibrous septum (Valve) covered by endothelium was seen projecting into the lumen (Fig. 7A).

Near its termination, the musculature surrounding the CS was quite thick - inner mostly circular, outer longitudinal; and some diverticulae were seen projecting between these muscle fibres (Fig. 7B).

\section{DISCUSSION}

The CS is a commonly used gateway to the left atrial and Left Ventricular (LV) epicardium. A wide array of diagnostic and 
mapping maneuvers to diagnose and treat arrhythmias is performed via the CS. More recently, the CS has become the target structure for LV epicardial lead placement to achieve cardiac resynchronization therapy. Cardiac resynchronization therapy and percutaneous mitral valve repair procedures, which modify the Coronary Sinus (CS) geometry, have led to a renewed interest in the anatomy of the coronary venous system. ${ }^{18}$

Ammer Habib et al. (2009) found the length of CS between $30-55 \mathrm{~mm} .{ }^{1}$ whereas Sanket Shah et al. (2012) described its average length ranging from $45-63 \mathrm{~mm} .{ }^{13}$ We have found the average length of CS as $29.82 \mathrm{~mm}$ (19.03$54.32 \mathrm{~mm})$. This variability in the length of CS may be accounted for by the variability of the sizes of heart. It may also be dependent on the shape of the CS, which has been described in the literature as cylindrical, funnel shaped.16 wind sock shaped, filiform, varicoid or high riding CS. ${ }^{13}$

The shape of CS ostium in the majority (96.1\%) was found to be oval and in only $3.84 \%$ it was circular in the present series.

Anatomy of the CS ostium assumes the great significance for performance of any selective procedures like ablation of node in the CS or in left atrium for various types of arrhythmias. Success or failure would to a considerable extent would depend upon thorough appreciation of this anatomy. Maasarany et al. (2005) have found mean height of CS ostium to be $7 \mathrm{~mm}(5-9 \mathrm{~mm})$ and mean width of $12 \mathrm{~mm}(7-16 \mathrm{~mm}){ }^{16}$ Mak et al. (2009) observed considerable variations and have described the diameter under two catagories: a) With Thebesian valve the transverse and craniocaudal dimensions was recorded as $7.3 \pm 2.8 \mathrm{~mm}$ and $7.9 \pm 2.7 \mathrm{~mm}$ respectively and b) With no thebesian valve $9.4 \pm 2.9$ and $9.3 \pm 2.9 \mathrm{~mm}$, respectively. ${ }^{18}$ Silver MA et al. (1988) had also observed that the maximum diameter of the CS ostium tended to vary inversely with the extent of the Thebesian valve. ${ }^{19}$

Matsuyama et al. (2010) found the mean surface area and diameter of the CS opening to be $43.7 \pm 17.3 \mathrm{~mm}^{2}$ and $10.5 \pm 2.8 \mathrm{~mm}$, respectively. ${ }^{20}$ In the present study average transverse diameter $=11.19 \mathrm{~mm}$. $($ Range $=4.02-16.91 \mathrm{~mm})$ and average vertical diameter $=7.92 \mathrm{~mm}$. (Range $=3.61-15.12 \mathrm{~mm}$ ). Our findings are in agreement with that of Maasarany et al. (2005) and Mak et al. (2009), Matsuyama et al. (2010) have reported a greater diameter, but have not specified which of the diameters that they are referring to.

Maasarany et al. (2005) found the presence of Thebesian valve in $87.5 \% .{ }^{16}$ Mak et al. (2009) reported it being present in $73 \% .^{18}$ Hellerstein et al. (1951) referring to the work of Yater (1929) showed this valve to be absent in $14.7 \% .^{9}$ Sanket S. Shah et al. (2012) reported it to be present in $73-86 \%$ of hearts examined. ${ }^{13}$ In the present series it was present in $82.6 \%$. This finding roughly corresponds well with that of other workers in the field.

In the present study the shape of Thebesian valve was found to be semilunar in $75 \%$ of hearts studied; it was found to be fenestrated in $5.76 \%$ cases and in $3.84 \%$ the valve showed fenestration as well as fibrous band. Pejkovic et al. (2008) have quoted the work of Esperanca Pinna (1973) who classified Thebesian valve between 6-12 types. The valve may contain muscular fibres. ${ }^{10}$ Mak et al. (2009) have reported that most of the valve were semilunar in shape (65\%); in $17 \%$ it was either band like or strand like. They found fenestration of the valve in $26 \%{ }^{18}$ Hellerstein et al. (1951) found multiple fine strands or threads in addition to the crescentic fold. ${ }^{9}$ Sanket S. Shah et al. (2012) found that valve is fenestrated in $16 \%$ of hearts. The incidence of semilunar valve in the present series is close to that observed by other workers. ${ }^{13}$

Maasarany et al. (2005) have stated that the Thebesian valve did not cover more than one third of the ostium. ${ }^{16}$ in contrast to this Mak et al. (2009) found that in $27 \%$ the valve covered at least $75 \%$ of the ostium whereas in $18 \%$ it covered just $10 \%$ of the ostium. ${ }^{18}$ Although Sanket S. Shah et al. (2012) have stated that the valve may cover $75 \%$ of the ostium. ${ }^{13}$ In the present series Thebesian valve was found to cover $75 \%$ of the ostium in $25 \%$; it covered $50 \%$ of the ostium in $26.92 \%$ cases and only $25 \%$ of the ostium in $30.7 \%$. Larger size of the valve narrows the ostium considerably and may produce an obstruction to the passage of catheter into the sinus.

\section{HISTOLOGY}

CS shows the three discrete layers of endocardium, myocardium and epicardium.

Michel Chauvin et al. (2000) have described a histological continuity between the right atrium and the left atrium through the coronary sinus myocardium using longitudinal plane sections. The connections are made of striated muscle fibers arranged in 2 distinct parts: a muscular cuff surrounds the coronary sinus wall along 25 to $51 \mathrm{~mm}$ of its length and other fibers emerge from this cuff to join the left atrial myocardium. ${ }^{22}$

Myocardial bundle can be seen to arise from the base of the left atrial appendage to divide into a splay of myocardial fibers that intervine with the fibers on the superior surface of the CS. Atriocoronary sinus bundle appears to be an extension of the anterior interatrial bundle of Bachmann (Adrian barcelo et al. 2004). ${ }^{3}$

Spatial distributions of CS musculature may have a role in the pathology of AVNRT. Antz et al. (1998) confirmed the existence of CS - LA connections histologically in Dogs heart. ${ }^{21}$ Antz M et al. (1998) have described that the CS musculature is continuous with left atrial myocardium in the proximal portion of the coronary sinus and with right atrial myocardium at the coronary sinus ostium. ${ }^{21}$

Bachmann's bundle is continuous anatomically and electrically with the myocardial muscular bundle described as atriocoronary sinus bundle that links the base of the left atrial appendage to the myocardial musculature of the CS. ${ }^{3}$

Sun Y et al. (2002) while doing retrograde CS angiography demonstrated a CS diverticulum in $21 \%$ Coronary Sinus Accessory Pathway (CSAP) patients. ${ }^{23}$

In the present study in all specimens, wall of the coronary sinus was surrounded by a cuff of striated muscle extending from the ostium. Striated myocardial connections of varying number and morphology left this coronary muscle cuff and connected to the left atrium; they ranged from 1 to 2 fascicles to a widely intermingled continuum. The valve of Vieussens was found in 6 hearts at a mean distance of $3.4 \pm 3.2 \mathrm{~mm}$ from the distal extremity of the coronary sinus muscle cuff. 22

\section{SUMMARY AND CONCLUSION}

The structure of CS is more like diminutive cardiac chamber for it has classically all the three layers viz. endocardium, myocardium and epicardium, unlike the structure of a vein.

Anatomy of the CS ostium and Thebesian valve assumes great significance whenever an interventionist attempts to negotiate a catheter into the CS for performance of any selective procedures like ablation of node in the CS or in left atrium for various types of arrhythmias. Cardiac resynchronization therapy and percutaneous mitral valve repair procedures which modify the Coronary Sinus (CS) geometry have led to a renewed interest in the anatomy of the coronary venous system. The CS is a commonly used gateway to the left atrial and Left Ventricular (LV) epicardium. Success or failure to a considerable extent would depend upon thorough appreciation of this anatomy. Spatial distributions of CS musculature may have a role in the pathology of AVNRT.

In the present study the average length of the CS was approx. $30 \mathrm{~mm}$; in the majority $(96.0 \%)$ the CS ostium was oval and its average transverse and vertical diameters were 
approx. $12 \mathrm{~mm}$ and $8.0 \mathrm{~mm}$ respectively. In most of the cases (84.0\%) CS ostium was guarded by Thebesian valve, which in the majority $(74.0 \%)$ was semilunar in shape. The valve covered $3 / 4^{\text {th }}$ of the surface area of the ostium in $24.0 \%$ cases.

The presence of myocardial fibres in the wall of CS and their arrangement in the form of circular, longitudinal and tangentially arranged fibres may have regulating function on the flow of blood in the CS. The connection of the muscle fasciculi with the left musculature and in turn with the musculature of the right atrium may have selective role in the conduction and propagation of conduction and act as an accessory pathway. As no work of this nature has been carried out in the population of Central India, the findings of the present work assume great significance.

\section{REFERENCES}

1. Ammar Habib, Nirusha Lachman, Kevin N Christensen. The anatomy of the coronary sinus venous system for the cardiac electrophysiologis.

Europace 2009;11:15-21.

2. Anderson KR, Ho SY, Anderson RH. Location and vascular supply of sinus node in human heart. British Heart Journal 1979;41:28-32.

3. Adrian Barcelo, Luis M, De La Fuente, et al. Anatomic and Histologic Review of the Coronary Sinus. Int J Morphology 2004;22(4):331-38.

4. Susan Standring, Neil R Borley, Patricia Collins, et al. Eds; Chapter - Heart and Great Vessels In: Gray's Anatomy. 2008, 40 th Ed. Churchill Livingstone Elsivier. Edinburg. 959-98.

5. Cornelius Rosse, Penelope Gaddum Rosse Eds; Chapter The Pericardium, The Heart and the Great Vessels: In. Hollinshead's Textbook of Anatomy. 1997, $5^{\text {th }}$ Ed. Lippincott Raven, Philadelphia, Newyork. 472-73, 480-81.

6. Richard S Snell. Chapter - The Thorax Part II - The Thoracic Cavity in Clinical Anatomy. 2004, $7^{\text {th }}$ Ed. Lippincott Williams \& Wilkins. 111,115 - 16, 120-21.

7. Ortale JR, Gabriel EA, Lost C, et al. The anatomy of the coronary sinus and its tributaries. Surgical and Radiological Anatomy. 2001;23(1):15-21.

8. Anh DJ, Eversull CS, Chen HA, et al. Characterization of human coronary sinus valves by direct visualization during biventricular pacemaker implantation. Pacing Clinical Electrophysiology. 2008;31(1):78-82.

9. Hellerstein Herman K, J Lowell Orbison. Anatomic Variations of the Orifice of the Human Coronary Sinus. Circulation. 1951;3:514-23.

10. Pejkovic B, I Krajnc, F Anderhuber, et al. Anatomical Variations of the Coronary Sinus Ostium Area of the Human Heart. The Journal of International Anatomical Medical Research. 2008;36:314-21.
11. Coakley JB, T Summerfield King. Cardiac Muscle Relations of the Coronary Sinus, The Oblique Vein of the Left Atrium and the Left Precaval Vein In Mammals. Journal of Anatomy. 1960;93(1):30-34.

12. Shinbane JS, Girsky MJ, Mao S, et al. Thebesian valve imaging with electron beam CT angiography: implications for resynchronization therapy. Pacing Clinical Electrophysiology. 2004;27(9):1331-32.

13. Sanket S Shah, Shawn D Teague, Jimmy $\mathrm{C} \mathrm{Lu}$, et al. Imaging of the Coronary Sinus: Normal Anatomy and Congenital Abnormalities. Radiographics. 2012;32:991-1009.

14. Drury RAB, Wallington EA, Sir Roy Cameron. Carlton's Histological Technique. 1967, $4^{\text {th }}$ Ed. Oxford University Press Newyork, Toranto. 129-30, 167-69, 214-15, 179-80.

15. Culling CFA. In Handbook of Histopathological and Histochemical Techniques. 1974, $3^{\text {rd }}$ Ed. Butterworths, London. 211-16, 414-16, 420-21.

16. Maasarany Shirley El, Colin G Ferrett, Anthony Firth, et al. The Coronary Sinus Conduit Function: Anatomical study (relationship to adjacent structures). Europace. 2005;7:475-81.

17. Bates RJ, Toscano M, Balderman SC, et al. The Cardiac Veins and Retrograde Coronary Venous Perfusion. Annals of Thoracic Surgery 1977;23:83-90.

18. Mak Gary S, Alexender J Hill, Florin Moisuic, et al. Variation in the Thebesian Valve anatomy and Coronary Sinus Ostium. Europace 2009;11:1188-92.

19. Silver MA, Rowley NE. The functional anatomy of the human coronary sinus. American Heart Journal. 1988;115(5):1080-84.

20. Matsuyama Taka-aki, Hatsue Ishibashi-Ueda, Yoshihiko Ikeda, et al. The Positional Relationship between the Coronary Sinus Musculature and the Atrioventricular Septal Junction. Europace 2010;12:719-25.

21. Antz Matthias, Kenichiro Otomo, Mauricio Arruda, et al. Electrical Conduction Between the Right Atrium and the Left Atrium via the Musculature of the Coronary Sinus. Circulation. 1998;98:1790-95.

22. Michel Chauvin, Dipen C Shah, Michel Hai Ssaguerre, et al. The Anatomic Basis of Connections between the Coronary Sinus Musculature and the Left Atrium in Humans. Circulation 2000;101:647-52.

23. Sun Yingxian, Mauricio Arruda, Kenichiro Otomo, et al. Coronary Sinus-Ventricular Accessory Connections Producing Posteroseptal and Left Posterior Accessory Pathway: Incidence and Electrophysiological Identification. Circulation 2002;106:1362-67. 